\title{
TOURISM SYSTEMS THINKING: TOWARDS AN INTEGRATED FRAMEWORK TO GUIDE THE STUDY OF THE TOURISM PHENOMENON
}

\author{
SANTIAGO RODRIGUEZ-GIRON AND DOMINIQUE VANNESTE \\ Division of Geography and Tourism, Department of Earth \& Environmental Sciences, \\ Faculty of Sciences, University of Leuven, Leuven, Belgium
}

\begin{abstract}
Tourism is widely recognized as a complex phenomenon. Some academics, however, have studied tourism from their own specialization, contributing from the perspective of their specific fields. Others have argued that the complexities of tourism should be tackled more systemically and so have used diverse concepts from systems thinking theory. Nevertheless, nobody has yet presented an integrated framework connecting existing diverse systems thinking concepts, which serves as a more structured point of departure from which to study tourism. This article (1) starts by identifying seven complexities of tourism, (2) discusses eight systems thinking's key notions in the context of those complexities, (3) structures an integrated tourism systems thinking conceptual framework, and (4) provides an application example. Thus, this work contributes with a more structured theoretical foundation for the study of tourism as a system and with an integrated approach to understand its complexities.
\end{abstract}

Key words: Tourism studies; Systems thinking; Complexity; Integrated framework

Introduction

Tourism is widely recognized as a complex phenomenon to describe (Brouder \& Fullerton, 2015; Darbellay \& Stock, 2012; Judd, 2006; Nicolau, 2013; Pearce, 2008; Pearce, Tan, \& Schott, 2007; Smith, 1994), and it is much more than "an industry" (McKercher, 2014). In this way, several authors have pleaded for a more systemic approach to tourism (Baggio, 2013; d'Hauteserre, 2006; Goeldner \& Ritchie, 2003; Leiper, 1979; Ritchie \& Crouch, 2003 ) that allows an integrative study of its complex nature. However, many authors approach tourism as a system based on the notion of the tourism industry (Ford, Wang, \& Vestal, 2012; Mill \& Morrison, 1985; Milne \& Ateljevic, 2001; Mosedale, 2006; Papatheodorou, 2004; Thomas, Shaw, \& Page, 2011), or industries (Leiper, 2008). This approach uses concepts such as production, products, distribution, supplying firms, consumers, and business as its discursive terminology, which puts the focus mostly on the commercial side of tourism.

Other authors suggest that interdisciplinary approaches may produce a richer understanding of 
tourism (Darbellay \& Stock, 2012; Hall \& Page, 2014; Ioannides \& Debbage, 2014). Decades of academic effort from specialized disciplines such as geography, economics, and sociology led to "disciplinary fragmentation and specialization" (Darbellay \& Stock, 2012, p. 448), hindering tourism studies from developing stronger theoretical bases. The call is thus to advance on theoretical constructs for tourism (Farrell \& Twining-Ward, 2004; Hall \& Page, 2014; Ioannides, 2006) that address its complexity in a more integrative way.

Therefore, this article aims to identify the complex aspects of tourism; discuss systems thinking's key notions and its utility to address the complexities of tourism; and structure an integrated tourism systems thinking conceptual framework to study tourism as a complex phenomenon.

We argue that a systems thinking approach to tourism, stemming from complexity sciences (Jafari \& Xiao, 2016; Lohmann \& Netto, 2017; Speakman, 2016), extends beyond industrial paradigms and "provides a potentially useful alternative framework for providing insights into the underlying dynamics of tourism development" (Russell \& Faulkner, 1999, p. 411). In this article, a complex system is considered a group of closely interconnected elements, which collectively generate diverse outcomes with emerging properties that differ from those of its constituent elements, in constant interaction with its environment and without a centralized organization (Baggio, 2008; Dekkers, 2015; Mella, 2012). This complements Network theory, which argues that "actors do not act in isolation, but in networks of relations, which affect their behavior" (Jørgensen, 2017, p. 313). Further, a system can also be defined as a set of networking elements; and a network can be defined as a set of elements behaving as a system (Baggio, 2017). In any case, we argue for moving from deterministic and fragmented ways of describing the tourism phenomenon to more dynamic and integrative ones.

The definition of complex systems makes it clear that tourism is a complex system (Speakman, 2016) and this complexity has to be embraced (Leiper, 2008). Complex systems are not virtual frameworks; they do exist in reality (Farrell \& Twining-Ward, 2004). Systems thinking provides the conceptual principles to tackle that complexity, acting as heuristic tools to reflect upon real phenomena and facilitate more integrative perspectives (Albert, 1995; Mai \& Smith, 2015; McBride, 2005; Speakman, 2016). Hence, the structuration of a tourism systems thinking-based terminology represents a challenging (Speakman, 2016) but promising task.

Tourism researchers are traditionally viewed as specialists in, for example, economy, geography, and sociology, with an interest in tourism. There is no such thing as tourismologists and tourism studies constantly borrow paradigms from other disciplines. This leads to referring to tourism in terms from specific fields, which fall short of depicting the diverse nature of the phenomenon. As Tribe and Liburd (2016) argued, "we should maintain a vigilant watch on whose interests are being served and whose are overlooked through the tourism knowledge system and how power can form and distort the field" (p. 58).

Moreover, beyond the academic sector, there is the need for other actors (visitors, residents, firms, governments, associations, and nongovernmental organizations) to expand their mindset about tourism (Forrester, 2007) if they want to understand why efforts do not develop as expected. Bramwell and Lane (2013) argued that, to tackle the challenges of sustainable development, it is important to have educational approaches that enhance public understanding of complex issues and the capacity to think systemically. Deterministic and industrial analogies of consumption-production cannot explain undesired results, such as failure to attract visitors, excessive numbers of visitors, inability for collective action, and local actors' exclusion (Lansing \& Vries, 2006). Actors need to improve their ability to look into the aggregated layers of the tourism system to comprehend its structure and dynamics, as well as the interactions with its broader environment (Bramwell \& Lane, 2013; Mai \& Smith, 2015). Development opportunities are diminished when destinations approach tourism only in terms of products to be sold, without considering the broader context and implications. This is typical of the case of destination management organizations (DMOs), which in practice behave mostly as destination marketing organizations (Pike \& Page, 2014).

We argue that systems thinking allows an approach to tourism as the multifaceted and dynamic 
phenomenon it is, facilitating the integration of inputs from different perspectives (McDonald, 2009), to reflect on how to leverage efforts in ways not possible only from commercial perspectives.

This article first describes seven aspects in the complexity of tourism and subsequently discusses eight systems thinking key concepts. Throughout the discussion, each concept is translated into the context of tourism, while arguing on its utility to tackle the complex aspects of tourism. Thereafter, we present an integrated tourism systems thinking conceptual framework to facilitate the study of tourism as a complex phenomenon. Finally, we discuss the framework's analytical applicability and present an example.

\section{The Complexities of Tourism}

The United Nations World Tourism Organization (UNWTO) defined tourism as "a social, cultural and economic phenomenon ... for personal or business/professional purposes . . . some of which imply tourism expenditure" (UNWTO, 2014, p. 1). This definition already goes beyond the perception of tourism as merely a leisure-related activity (Urry \& Larsen, 2011) or as an industry (Ford et al., 2012; Leiper, 2008; Milne \& Ateljevic, 2001; Mosedale, 2006; Papatheodorou, 2004). Tourism "is not restricted to the considered 'typical' tourism activities, such as sightseeing, sunbathing, visiting sites, and practising or watching sports" (United Nations \& UNWTO, 2010, p. 2). These notions describe such a diverse phenomenon that the easiest way to identify tourism visitors would be to posit that anyone, regardless of the distance traveled or activity performed, is a tourism visitor provided they do not intend to migrate or to earn income from an entity at the destination (United Nations \& UNWTO, 2010). Hence, tourism represents one of the largest and most recurrent phenomena of human mobility worldwide (Dubois, Peeters, Ceron, \& Gössling, 2011).

With this overarching conception of tourism in mind, we will discuss seven aspects of its complex nature. Although this list is certainly not exhaustive, it synthesizes crucial aspects widely discussed in existing literature.

First, people and organizations are subject to diverse motivations and conditions for participating in tourism. The range of expectations can be as diverse as the number of visitors or destinations. Simultaneously, each actor is subject to particular circumstances such as time, budget, demographic characteristics, laws and policies, cultural and social practices, and physical and cultural distance (McKercher, 2008; McKercher \& Zoltan, 2014). This mix of motivations and circumstance generates an immense diversity of visitors' and destinations' profiles and needs (United Nations \& UNWTO, 2010).

Second, each visitor interacts with a multiplicity of facilitators, within commercial and noncommercial contexts, for the realization of the desired experience (Darbellay \& Stock, 2012). Tourism facilitators include a wide range of actors (Baggio, 2017), including residents, firms, governments, and associations (Ioannides \& Debbage, 1998), while the interactions that generate tourism experiences happen at different moments and places, adding to tourism's complexity (Darbellay \& Stock, 2012; Mai \& Smith, 2015).

Third, the tourism phenomenon emerges with a wide diversity of forms and outcomes (Darbellay \& Stock, 2012; Van der Duim, Ren, \& Jóhannesson, 2013). These range from independent travelers, to itineraries customized by a tour operator, to prearranged standard group packages (Pearce, 2008). Even within the same territory, visitors can be either excursionists or tourists, domestic or international, implying different types of dynamics and impacts, which increase the complexity of the tourism phenomenon.

Fourth, tourism is a multidimensional phenomenon (Darbellay \& Stock, 2012), fundamentally of a social nature, but with environmental impacts and very often with commercial implications (UNWTO, 2014). This is true to the extent that no commercial firm is part of a tourism experience without the involvement of a visitor, although some tourism forms may emerge without the participation of a commercial firm. Therefore, the multidimensional nature of tourism is inherent to its complexity.

Fifth, tourism is characterized by its multiscalarity, because the phenomenon can cover different geographical, organizational, social, and political scales (Baggio, 2017; Darbellay \& Stock, 2012). This applies not only to the case of international visitors who link the local and the global (Milne 
\& Ateljevic, 2001). Multiscalarity can also relate to local visitors entering a natural park, managed by a national authority, and subject to international policies, as in the case of World Heritage sites. So, multiple-scale relationships are established during the visitors' journeys.

Sixth, tourism is vulnerable to influences, because it does not occur under centrally controlled conditions as in a laboratory or an assembly plant. Tourism emerges from continuous interactions that simultaneously influence and are influenced by their environment. While the tourism experience is taking place, actors are exposed to dynamic, noncentrally controllable, and interdependent factors (Dekkers, 2015), such as culture, nature, society, laws, politics, and economy (Hartman, 2016).

Seventh, tourism is, in essence, an intangible individual experience perceived in a subjective way by each actor (Judd, 2006; Nicolau, 2013; Pearce, 2008). Tourism takes raw material and services not merely to assemble new products; its outcomes are of a different nature. Tourism outcomes take the form of experiences generated by interactions (Darbellay \& Stock, 2012). Visitors are not passive actors in such experiences (Perkins \& Thorns, 2001), because tourism does not exist until visitors get fully involved (Smith, 1994). Conversely to industrial processes, in tourism: visitors travel to the place of interest, instead of sending a product to the consumer; the real experience cannot be tested beforehand, as in the case of products and services; and it is impossible to replicate two identical experiences, whereas industrial assembly lines can replicate identical products (Nicolau, 2013; Smith, 1994).

\section{Translating Systems Thinking Into Tourism}

In this section, we discuss and contextualize eight concepts of systems thinking as more integrative notions to tackle the seven abovementioned complexities of tourism. It is important to mention that these concepts are not new; to discuss them in the context of tourism and to connect them in a structured way to conduct tourism system analysis is. The discussion in this section points out some relationships between systems thinking and Network and Actor Network theories, because they all contribute to a more integrative approach to tourism as a complex phenomenon.
The eight concepts discussed below are the building blocks of the integrated framework introduced later in Figure 1. The concepts were chosen based on the necessity to move from "inside" towards "outside" the different aggregation levels of tourism as a system. In other words, it is based on the necessity of identifying individual and simpler components and going through increasing levels of aggregation and complexity. Thus, the concepts are organized in three categories. First, the system's Components identify and describe the tourism system itself and its functioning. Second, the system's Structure makes sense of the relationships between the identified components. And third, the system's Properties explain key characteristics emerging from the progressive aggregation of multiple components, as it happens in the tourism phenomenon.

\section{The First Concept Is "Element"}

This refers to "the smallest parts needed for the purposeful analysis of a system within a specific study" (Dekkers, 2015, p. 19). An element can be a system on its own, but this component may or may not be divided into subcomponents depending on the desired level of analytical detail. This is the simplest level of the system.

For tourism, we consider the tourism actors (visitors, residents, firms, governments, associations, nongovernmental organizations, and academia) as the basic interacting elements of the system. However, Actor Network Theory (ANT) calls for considering nonhuman elements, such as objects, machines, and technologies, as actors as well, because it is thanks to them that "emblematic tourist performances involve and are made possible and pleasurable" (Van der Duim et al., 2013, p. 8). It can be argued that such nonhuman elements are merely resources that receive a meaning when enacted by human actors. However, it is also true that complex natural or artificial objects, such as ecosystems (e.g., a national park) and crowd-sourced information platforms (e.g., TripAdvisor), have their own behavior influencing the emergence of the tourism experience. This allows consideration of, for example, natural or technological nonhuman objects as actors within the tourism system. We consider that such an approach is useful for a more integrative and sustainable view of tourism, because it helps 
restrain economic views and profit maximization from becoming the only key factors (Bramwell \& Lane, 2013). Thus, the notion of element tackles the complex aspect of multiplicity of visitors and facilitators in tourism, because it allows the identification of actors in the system of interest. The identification of the actors and their relationships depends on the chosen analytical depth. For example, at the individual level (a visitor, a firm, a government), at the group level in a region (a segment of visitors, a firm's association, a commonwealth of municipalities), or at the multigroup level (two regions with diverse actors acting collectively). Hence, if the chosen analytical level is at the group level, it is not necessary to describe the subcomponents of the group's members (individual characteristics such as size, departments, units). The analytical depth would stay at the level of the group's function as a whole within the system and on its relationships with functions of the other actors (other elements).

\section{The Second Concept Is "Function"}

This is a process that transforms energy from one state into another. Performing a function means to take a resource, to process it in a set of stages, and to deliver an output (Dekkers, 2015; Hoff, 1992). This notion is useful in identifying the elements' individual and collective behavior.

The tourism phenomenon emerges from the aggregation of functions performed by visitors, facilitators, and nonhuman actors, such as ecosystems or technological platforms. The behavior of these tourism actors (i.e. the system's elements) determines the final experience. They have certain resources, such as time, budget, logistics, information, and energy. Through their interactions, at different moments and locations, resources are transformed into tourism experiences (Chen, Zhang, Huang, \& Xie, 2013; Mahner \& Bunge, 2001). A functional approach helps to tackle tourism's complex aspect of multiplicity of visitors and facilitators and diverse motivations and conditions to engage in tourism, because it focuses on the actor's motivations and roles. This explains interactions better than merely describing independent characteristics. For example, in the case of an inbound tour operator, instead of describing only its size and products, a functional approach acknowledges the resources it requires and its motivations to act. In this way, the implications of the operator's actions can be understood not only in the economic sphere, but also in the social and environmental aspects. This moves inquiry from what or who, which only provides characteristics, into how and why, which provides explanations.

\section{The Third Concept Is "Dynamics"}

Systems change over time, so it is necessary to understand their dynamics (Dekkers, 2015) by examining at their elements' functions (Ghosh, 2015) and how these affect the outcomes (Mella, 2012). By understanding the dynamics between the elements' functions, we might better understand the functioning of the system as a whole (Arnold $\&$ Wade, 2015).

In tourism, dynamics help us understand the rules that govern the system at the local level (e.g., host communities) and at the macrolevel (e.g., international law-making bodies such as the European Union) (Meekes, Parra, \& de Roo, 2016). Zahra and Ryan (2007) suggested that complexity theory and chaos theory both contribute concepts to identify components and dynamics in social systems. This can be done, for example, through Causal Loop Diagrams, which display the feedback loops among the system's elements caused by their interactions (Mai \& Smith, 2015; Nguyen, Bosch, \& Maani, 2011). For example, to differentiate dynamics that facilitate working towards common goals from those that prevent collective achievement. The concept of dynamics is thus useful in addressing the complex aspect of diversity of tourism forms and its sensitivity to influences. And, as tourism interactions occur at different geographical scales and affect different spheres (social, economic, environmental) (Nicholls, Amelung, \& Student, 2017), the concept of dynamics is also useful in studying the aspects of multiscalarity and multidimensionality of the tourism system.

\section{The Fourth Concept Is "Environment"}

A system has boundaries (not necessarily physical) and thus operates within an environment (Dekkers, 2015). This is the total sum of resources and other systems outside the boundaries of the 
system of interest that provide input to the system and consume its outputs. The system's elements have a certain autonomy, but its boundaries end the moment the system interacts with other independent systems (Mingers, 2006). The environment encapsulates all of the system's aggregation levels. This is why the overall function of a system is said to be relative to its environment (Mella, 2012).

This is highly relevant because actors generate the tourism experience by interacting with a range of non-tourism-specific systems and resources (e.g., public roads or protected areas, country entry requirements or practices of host communities, and markets and public spaces used by residents). A diverse environment able to provide many resources is needed for tourism to emerge. And the notion of open systems emphasizes that tourism does not occur in a vacuum because its outcomes simultaneously shape and are shaped by its environment. Also, the idea that a complex system may not have physical boundaries relates to the notion that a "destination" does not necessarily refer to a static geographic space. Even among the same group of tourism facilitators, the territory of the destination they promote may vary. This depends on the visitors they deal with and the activities involved. Thus, the concept of environment explains tourism's complex aspects of sensitiveness to influences and multidimensionality as local or international actors and conditions may influence the tourism system outcomes.

\section{The Fifth Concept Is "Abstraction and Hierarchy"}

Abstraction is the removal of layers of detail to capture the essential features of a system (Mella, 2012), whereas hierarchy refers to structural levels of organization between larger and smaller systems (Ghosh, 2015; Mella, 2009, 2012). It is like the organizational diagram of a corporation that gives a structural overview (Ghosh, 2015; Lindsay, Downs, \& Lunn, 2003). A system can include different levels, and each level can represent a system of its own, encapsulating other subsystems (Mella, 2009), thus creating a hierarchy (Dekkers, 2015).

We argue that the tourism phenomenon is a system of systems. But regardless of the analytical depth, the tourism phenomenon emerges from the aggregation of interactions at different geographical and organizational levels (Martin \& Sunley, 2012). Revealing a system's structure network theory typically involves three levels: micro (each element's properties), meso (the intermediate structure of the system), and macro (the global characteristics) (Baggio, 2017). For example, a traveler (an element-microlevel) could directly interact with a hotel (another element-microlevel), or contract a tour operator (a subsystem-mesolevel), which integrates various other elements; and they all together, along with the environment they are immersed in, form the system (the macrolevel). Using abstraction and hierarchy, we can reveal complex structures to explain how initially independent elements and resources support a living phenomenon such as tourism. Abstraction and hierarchy are useful to tackle tourism's complex aspect of multiscalarity, by visualizing the different aggregation levels of actors and means (Arnold \& Wade, 2015) involved in tourism as a system.

\section{The Sixth Concept Is "Emergence"}

This refers to new properties and levels of organization, which develop from simpler elements that themselves do not possess such properties independently (Mella, 2009; Speakman, 2016). These new qualities are synthesized by the combination of dynamics between the elements' functions (Dekkers, 2015), as a result generating a novel phenomenon (Heylighen, 2009). This means that the outcome of a system goes beyond the simple addition of its elements' characteristics (Mella, 2009).

Similarly, the tourism experience does not emerge from the actors or means that facilitate it taken independently. Tourism emerges from the combination of interactions through visitor involvement facilitated by networked relationships among human and nonhuman actors (Jørgensen, 2017). Thus, it is the relations and not the elements themselves that produce the emergence of the tourism phenomenon (Van der Duim \& Caalders, 2008) as an experience that is more than just a collection of services and places. Tourism is a permanent manifestation of emergence that generates impressions and impacts with subjective meanings for the system's actors and in the environment. This is why industrial perspectives or deterministic analytical approaches 
fall short in tackling tourism's complexities. A hotel room, a relative's house, and attractive scenery have no value in and of themselves, because only the visitors' involvement catalyzes the emergence of the tourism phenomenon. Emergence thus explains tourism's complex aspect as an intangible individual experience.

\section{The Seventh Concept Is "Self-Organisation"}

It is a characteristic property of complex systems (Dekkers, 2015; Erçetin \& Banerjee, 2015) that refers to the emergence of global coordination out of local-level interactions. The dynamics between the system's basic elements produce structures and outcomes at higher and more complex aggregation levels. This gives the system the tendency to adapt in response to influences from its environment (McDonald, 2009). Self-organization relates to Distributed Leadership, which refers to a widespread leadership agency. It incorporates the activities of multiple groups of individuals and is constructed as a shared emergent process over time through interactions among leaders, followers, and their environment (Currie \& Lockett, 2011).

Self-organization defies the idea of tourism entities controlling the generation of the desired outcomes in a centralized way (Baggio, 2013). Along the same lines, network analysis demonstrates that actors within a destination may connect in varied ways, based on characteristics different from those usually considered from centralized deterministic managerial perspectives, such as location or type (Baggio, 2017). For example, distributed leadership refers to the case of organizations supporting long-haul international tourism experiences, which requires a range of leaders to work together at a physical, organizational, and cultural distance with different sets of skills and attributes (Benson \& Blackman, 2011). However, it does not mean that tourism should not be managed at all. Self-organization means that management approaches should focus on fostering efficient cooperative environments instead of striving for centrally controlled organizations (Speakman, 2016). Based on some essential policies, such as favoring service providers' diversity, a destination can strengthen its actors' self-organizing capacities and their adaptability in overcoming perturbations. Even highly influential
DMOs need to deal with self-organization, because destinations include varied actors (Ioannides \& Debbage, 1998), making it impossible to centrally coordinate all interactions (Mai \& Smith, 2015; Van der Duim et al., 2013). Nevertheless, as Russell and Faulkner (1999) argued, "chaos should not be seen as simply lack of order or a condition reflecting the degeneration of a system, but rather as a creative phase leading to a new, more complex order" (p. 414). Self-organization explains the complex aspect of diversity of tourism forms and outcomes and calls for new approaches to tourism development.

\section{The Eighth Concept Is "Nonlinearity"}

It refers to outputs not proportional to the inputted efforts and is the defining feature of complexity. This is generated by dynamics between the system's elements that aggregate at different levels, leading to situations that do not reproduce past trajectories (Erkoçak \& Açıkalın, 2015). In this context, small changes can have disproportionately large effects on the system (Bramwell \& Lane, 2013; Speakman, 2016). Gleick (1987) pointed out that nonlinearity is referred to in several ways: technically, it is known as Sensitive Dependence on Initial Conditions; it is also generally known as the Butterfly Effect; and in folklore it is said that: "for want of a nail, the shoe was lost; For want of a shoe, the horse was lost; For want of a horse, the rider was lost; For want of a rider, the battle was lost; For want of a battle, the kingdom was lost!"

Tourism does not work in a linear way, and the behavior of its actors does not produce fully predictable outcomes (Farrell \& Twining-Ward, 2004), because they act in complex nonlinear relational networks (Jørgensen, 2017): for instance, negative isolated events amplified by the media, leading to massive cancellations from a certain destination. Even the well-known Tourism Area Life Cycle (Butler, 1980) linear model recognizes that the final destination's fate is unpredictable, varying between different degrees of rejuvenation or decline (Zahra $\&$ Ryan, 2007). Nonlinearity is natural to the tourism phenomenon (Mai \& Smith, 2015) as its outcomes can hardly be understood through linear analysis (d'Hauteserre, 2006; Farrell \& TwiningWard, 2004). Although there may be clear targets 
and well-structured organizations in place, nonlinear and nonpredictable outcomes are typical in tourism destinations because many actors participate. Nonlinearity explains tourism's complex aspects of diverse motivations, multiplicity of facilitators, and vulnerability to influences, and reminds us to reflect on the adaptive responsiveness of the tourism system (Baggio, 2008).

\section{Tourism Systems Thinking}

So far, we have discussed the key concepts of systems thinking in the context of tourism and how each helps tackle different aspects in the complexity of tourism.

Now, the question is: How do these concepts interconnect to describe and study tourism in a more integrative way? This question is important to overcoming the perception that a systemsbased approach "is little more than an amalgam of methods, models and metaphors from a variety of disciplines rather than an integrated science" (Speakman, 2016, p. 7).

Therefore, in Figure 1, we present an Integrated Tourism Systems Thinking Conceptual Framework that formalizes a structured way of describing the tourism phenomenon. The framework is structured so that its concepts tackle the complexities of tourism in a progressive way: from individual components and less aggregated levels inside the system towards more complex aggregation levels and properties outside the system. In this way, we can conceptually zoom in to see the tourism system's basic components (the elements) or zoom out to study properties at higher aggregation levels of complexity (e.g., self-organization). This conceptual integration makes it possible to analytically "dissect" a tourism system of interest while maintaining an integrated view between the parts and the whole system.

Based on this integrated terminology, we can now propose the following description of how tourism works: the elements (the actors) of the tourism phenomenon perform functions (the actors' roles), whose dynamics (actors' interactions) progressively aggregate while simultaneously being influenced by and influencing their environment (actors and other systems outside the system). The aggregation levels of the tourism phenomenon can be abstracted (capture the essential features) to study their hierarchy (levels of structural organization). This, in turn, helps explain the emerging (previously nonexistent) characteristics embedded in the final tourism experience, the actors' degree of

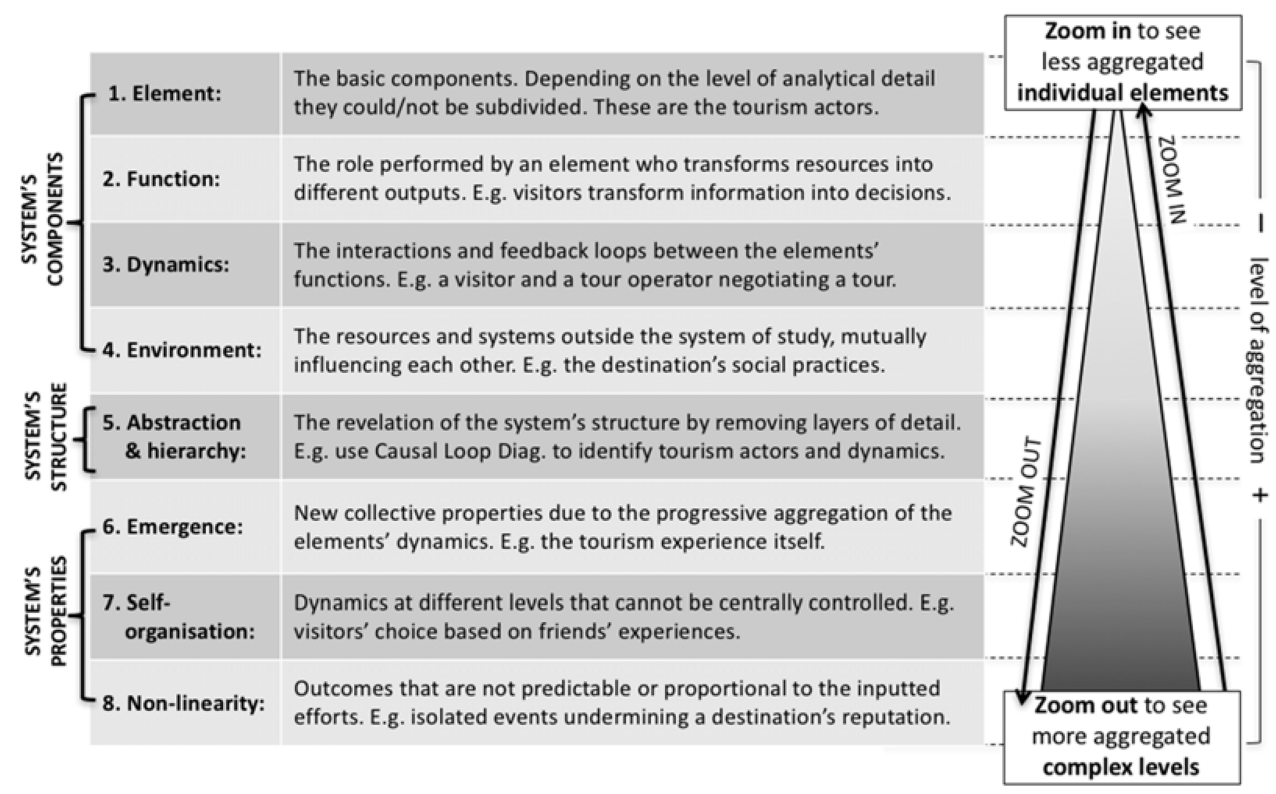

Figure 1. An integrated tourism systems thinking conceptual framework. Source: Authors' elaboration. 
self-organization (dynamics noncentrally controllable) and the system's nonlinear (outcomes not proportional to the inputted effort) behavior.

Such a systemic description offers an open approach to tourism as a dynamic phenomenon with a neutral starting point for its study. This avoids the insertion of predetermined connotations, such as commercial or industrial analogies. In this way, the possibility of addressing tourism from multiple perspectives remains preserved. The framework (Fig. 1) analyzes tourism using three sets of interrelated systems thinking concepts: (1) concepts 1 to 4 for the system's Components, (2) concept 5 for the system's Structure, and (3) concepts 6 to 8 for the system's Properties. In the following, we discuss why these concepts form part of the framework and how they relate to each other.

First, the concept of element represented by the human and nonhuman tourism actors allows approaching tourism cases that may not have any commercial connotation (e.g., a resident hosting a relative during a weekend). Although these persons may incidentally perform activates involving monetary transactions, such as going to a restaurant or visiting a museum, the experience does not have a commercial context. In any case, the concept of element allows referring to both noncommercially related tourism cases and commercially related tourism cases.

Second, the notion of function proposes approaching the tourism actors (elements) from the perspective of their roles within the system under study. In this way, the actors and their functions go together as the basic descriptors of the tourism system and its behavior. By emphasizing the actors' functions rather than on their individual characteristics we naturally think in terms of connective interactions between the actors. This is because the participation of an actor within a tourism system makes sense in terms of its interactions with others. For example, a tour operator or a resident is identified as a system's actor (or not) provided that it directly participates in the facilitation of the tourism experience.

Third, the ideas of functions and interactions among the actors connect our analysis with the idea of dynamics. This concept reminds us how interactions aggregate at different levels. A multileveled perspective is important because tourism dynamics are generated by diverse actors (e.g., visitors, firms, residents), performing varied functions (e.g., information search, booking, transportation), at different locations (source market, in route, or at destination). Some dynamics have a local scope, such as getting recommendations from a friend, while others have an international scope, such as taking an international flight. This points to the observation of how interactions generate reactions that produce new interactions in response, and how these dynamics ultimately facilitate or hinder the tourism experience.

Fourth, as dynamics among the actors continue to aggregate at diverse moments and places, their effects also reach actors and systems outside the system under observation. This leads us to consider the system's environment, which reacts by generating dynamics at a broader scale. This may be the case, for example, of governments, host societies, or public spaces, which, although not specifically oriented towards tourism, receive the impacts of tourism flows and react in the form of policies, changes in the attitude of hospitality, and physical deterioration.

Fifth, the concepts of abstraction and hierarchy remind us to maintain a connective view among the previously discussed system's components (elements, functions, dynamics, and environment). The intention is not to describe a perfectly structured, static scheme of tourism. The intention is to reflect throughout our analysis how the system's components interact and connect at different levels of aggregation. For instance, how a group of actors (e.g., a tour operator, accommodation services, certain attractions, and a community) forms a subsystem interacting at the local level, but also interacting with foreign distribution companies that represent other subsystems at the international level, while observing certain authorities' regulations that represent another subsystem in the system's environment. In this way, abstraction and hierarchy help reveal the system's essential structure.

Finally, the sixth, seventh, and eighth concepts of emergence, self-organization, and nonlinearity, respectively, describe key properties to keep in mind when trying to understand a tourism system's behavior. These properties manifest themselves progressively as a system reaches higher levels of aggregation and complexity. Tourism is a clear 
example of this, because it is the result of dynamics aggregated at different places and times. The property of emergence is embedded in the very nature of tourism. This is true to the extent that no tourism experience emerges without interaction with other actors, and the fact that the capacity to generate a tourism experience does not reside in any of the actors individually. In the same way, self-organization reminds us that although coordination can be enhanced in a tourism system, the full set of interactions and outcomes cannot be centrally controlled because of tourism's complex and dynamic nature. Even highly controlled and physically delimited tourism experiences offered in cases such as all-inclusive resorts are ultimately influenced by the broader social, political, or natural environments they are immersed in. In our analysis, nonlinearity calls for a constant observation of how apparently small details can have large, unpredictable effects on the whole system. This could be the case of destinations that spontaneously become famous by word of mouth and, in a few years, local residents witness tourism's unexpected transformation from a factor of life improvement into a factor of deterioration as a result of overcrowding. In summary, these properties remind us two things. First, to analyze tourism we must consider its changing and unpredictable nature throughout the process. Second, the further we zoom out or the closer we zoom in, the more levels of aggregation are revealed in the tourism system, and thus the properties of complexity are likely to manifest themselves more intensively.

\section{Applicability of the Framework}

Although the framework is conceived to allow multiple analytical perspectives, such conceptual openness also risks remaining too abstract for practical analysis. One important question is, therefore, how to operationalize these concepts to study the particularities of different tourism cases? Although a detailed exposition of possible procedures goes beyond the scope of this article, we present a brief example.

Our case study is Spanish-learning tourism in the city of Cuenca, in southern Ecuador. Four UNESCOrecognized sites coincide in Cuenca: the city center as Cultural Heritage (1999), the intangible Heritage of the Straw Weaving Hat (2012), the Biosphere Reserve (2013), and a section of the multinational Royal Andean Trial, Qhapaq Ñan (2014). However, the city performs poorly in terms of international visitors, with only 198,994 tourists, $14 \%$ of the 1,418,159 tourists to Ecuador (Ministerio de Turismo de Ecuador, 2017), arriving to Cuenca during 2016 (Grupo de Investigación en Economía Regional [GIER], 2017b). Of those, 9 out of 10 are independent travelers, more than half rely on family recommendations, and, especially in the first quarter of the year, it is probable that visitors stay for only 2 days (GIER, 2017a). This suggests that the destination does not have much influence on the visitors' decision-making or on their behavior once at the destination. For most foreign visitors, Cuenca is just a secondary destination within a larger itinerary taking them to Ecuador or South America. This is also partly because Cuenca has no international airport or borders, making it a sort of "continental island" in terms of international connectivity.

Within this context, in 2016, as part of a broader research project, three of the main Spanish schools in Cuenca were interviewed. Using the framework's concepts (Fig. 1), we briefly illustrate how to question and analyze this case with a systemic perspective, to reflect on its implications for tackling Cuenca's situation as a secondary destination.

The first set of concepts (system components) in the framework describes the system itself. First, the framework suggests that the system's basic components or elements must be identified, proposing that these elements are the involved actors. A useful question to identify these actors is: Who are the actors directly involved in the generation of the tourism experience under study? In other words, which elements are inside the system? In our case study, the two central actors are Spanish schools and the Spanish students. However, depending on the type of Spanish course offered, a varied combination of other actors, such as foreign education institutions, host families, accommodation services, and tour operators, among others, could also be directly involved. This question also helps identify where the actors are located. Second, the framework suggests that the functions performed by each actor involved must be observed. A useful question to describe functions is: What is the service or role that each actor plays? Thinking 
in terms of functions is important because things are better understood by describing what actors do (e.g., a Spanish school teaches a language) instead of describing their parts (e.g., the school's organizational structure). Further, a functional approach helps to reflect upon the actors' behavior and to identify the resources they require. In our case study, the Spanish schools, besides teaching a language, act as the central coordinators of educational programs with complementary activities to offer a culturally immersive learning experience. Other actors are involved depending on the activities included in each learning program, such as excursions, cooking lessons, or dancing lessons. Third, the framework invites reflection on the dynamics resulting from the identified functions among the actors. Useful items to describe dynamics are: how, when, and why actors interact or not with each other. We can now reflect on the dynamics among, for instance, visitors, Spanish schools, host families, and tour operators to generate a detailed and comprehensive understanding of how our case study's system works. Dynamics helps to think about aspects such as how visitors and Spanish schools get in touch, what makes students choose their destinations, how the process takes place from conception to involvement, who are the most influential actors in the process, whether the final experience meets expectations, and how these dynamics affect host societies. Fourth, to complete the description of the system, the framework proposes to describe its environment. A useful question to describe the environment is: Who are the actors, what are the circumstances and resources not directly involved (i.e., outside the system) in the tourism experience, but have an influence or are influenced by it? "Outside the system" or "indirectly involved," however, does not mean at all not important. Describing the system's environment helps taking into consideration key indirect factors, such as educational or governmental authorities, regulations or cultural context, and access routes for complementary activities, all of which have a determinant effect on the intended culturally immersive Spanish-learning experience.

The second set of concepts (system's structure) in the framework refers to abstraction and hierarchy. In the previous steps, we have identified the tourism system's components and recognized different levels of aggregation. Based on this knowledge, abstraction and hierarchy help to recreate the essential structure of the case study by structuring this new knowledge. Useful questions are: Who are the system's central actors? Who is connected to the system through the central actors in a second or third ring of connections? Who decides or what determines the configuration of the experience? Are those determinants inside the system or in its environment? Are decision-makers based locally or abroad? Do they influence only certain actors or the whole system? Based on these questions, we present a short example describing our case study's essential features and structure in terms of its actors, their functions, their dynamics, and the system's environment. Central actors are the local Spanish schools, whose function is offering courses, and the visitors whose function is learning Spanish. In some cases, Spanish schools managed to foster dynamics in the form trustworthy partnership with a foreign educational center, which allows them to reach students already taking Spanish courses in their home country. These are the most successful cases in terms of number of visitors and length of stay. Simultaneously, Spanish schools generate local dynamics incorporating local actors, such as host families, handicraftsmen, and tour operators depending on the configuration of the courses. The interviewed Spanish schools offer different types of courses. But in any case, once students are enrolled, they stay in Cuenca for periods ranging from 1 week, for short-term private lessons, to several weeks or even complete academic semesters valid as part of foreign educational programs. In general, these schools use a culturally immersive language-learning approach that combines Spanish lessons with experiential creative activities (e.g., cooking, dancing or handcrafting lessons), stays at local host families, and day or multiday excursions around the country. A determinant actor in the system's environment is the Ministry of Education, because Spanish schools have to comply with current legislation to operate.

Finally, the third set of concepts (system properties) recalls that, throughout the analysis, attention should be paid to the key properties of tourism as a complex system, which result from the aggregation of dynamics at different levels. Thus, the sixth concept refers to the emergence of new collective 
characteristics from this aggregation process. This points to the fact that although Spanish schools and visitors are the central actors moving the system, the final tourism experience is not something that they can generate by themselves. They depend on the other actors and circumstances from within the system as well as from its environment. The seventh concept reminds us of self-organization. Although Cuenca as a destination does not collectively promote language learning as its core tourism offer, several local and foreign actors have achieved a level of coordination for several initiatives of this kind to emerge and thrive. The eighth concept emphasizes nonlinearity. Spanish schools carefully structure their course programs and leverage the reputation of foreign partners to attract visitors. Nevertheless, isolated events, such as an accident during an excursion or the misconduct of a host family member, can instantly ruin the reputation of a study program that took years to introduce to a foreign educational center. In short, a system's properties remind us that we must remain open to identifying and understanding dynamics that could generate new or unexpected results.

This systemic approach reveals an interesting opportunity for Cuenca. Spanish-learning tourism is usually deemed an incidentally tourism-related activity in the city. Nevertheless, this tourism modality has proven its ability to overcome several of Cuenca's challenges as a destination in terms of attracting international markets. First, visitors stay for longer periods, from 1 week to several months, depending on the course they choose. Second, Cuenca becomes the main destination and logistic center for those students, capturing most of the visitors' expenditure, generating longer periods of stay, and reducing the need for constant fluxes of new visitors, which prevents the destination from overcrowding. And third, Spanish schools involve a range of local actors (e.g, host families, cooks, and artists), who usually do not have contact or feel a direct benefit from international visitors arriving through more conventional modalities such as tour packages or independent traveling. These characteristics of Spanish-learning tourism are especially important for Cuenca as a destination because they align with the vision of the city's 2016-2021 Tourism Development Plan (TurisConsulting \& ICOPMED Travel Cia. Ltda., 2016). Thus, Spanish-learning tourism should be considered as a higher priority by policymakers and local authorities.

There are several systems thinking-based approaches and tools that address tourism as a system and that could be useful complements for analytical purposes. For example, the Complex Adaptive Systems (CAS) approach is used to examine the conditions of adaptive areas (Mingers, 2006), as well as to discuss "how to manage CATS [Complex Adaptive Tourism Systems] in the context of complexity" (Farrell \& Twining-Ward, 2004, p. 276), whereas Causal Loop Diagrams (CLD) were used by Mai and Smith (2015) to address issues such as the "threats to tourism sustainability." These are some examples that apply certain systems thinking's concepts to address the complexities of tourism study. They can be positively complemented by using the integrated framework introduced in this article as their interrelated conceptual basis. This, in turn, will provide a mutual advantage for both perspectives: while tourism can be studied from more integrative and multidisciplinary approaches, systems thinking can be applied to tourism studies in a more structured and integrated way, overcoming the argumentation that it is nothing more than an amalgam of metaphors. Finally, for a detailed model and methodology to perform tourism analysis based on the conceptual framework introduced in this article, look for "An integrative model (iModel) for decision-making" by RodriguezGiron, Vanneste, and Ioannides (2018).

\section{Final Considerations}

Complexity is embedded in the very nature of tourism. The tourism phenomenon resists easy classification into one-dimensional, deterministic industrial paradigms or fragmented disciplinary approaches. The merit of applying an integrative, systems thinking terminology to facilitate the study of tourism is that it does not reduce the phenomenon to the domain of a specific discipline, maintaining its diverse and multilayered essence.

Systems thinking offers a set of principles that, in an integrated way, suit the challenge of studying tourism's inherent complexities from its elemental to its more complex aggregation levels. The tourism systems thinking integrated framework introduced in this article helps to (1) identify the elements of 
the tourism system (Dekkers, 2015), (2) focus on the functions of the elements in relation to the system as a whole (Mella, 2012), (3) study the dynam$i c s$ of the system to understand its behavior (Mai \& Smith, 2015), (4) recognize the mutual influences between the tourism system and its environment (Mella, 2012), (5) reveal the organizational structure of tourism systems through abstraction and hierarchy (Mella, 2009), (6) consider the emerging nature of the tourism phenomenon as something more than just the sum of its elements (Dekkers, 2015), (7) recognize that outcomes in complex systems do not depend on a centralized coordination but on self-organization emerging from local interactions (Farrell \& Twining-Ward, 2004), and (8) acknowledge that results may be nonlinear in relation to the invested efforts (Erkoçak \& Açıkalın, 2015; Meekes et al., 2016).

This is not just a combination of fancy concepts. The understanding of the real nature of tourism will continue to lag if industrial and deterministic notions remain the main referential descriptors to discuss the phenomenon (Mura \& Tavakoli, 2014). Whether intentionally or unintentionally, many scholars, students, governments, and practitioners will continue considering tourism a purely leisure-related activity with mostly economic importance. This reduces tourism to offer-demand dynamics and fragmented disciplinary approaches, with no reflection on the broader context, preventing the full realization of tourism's interconnected and virtually omnipresent effects on modern societies, natural environments, and economies. Therefore, the "tourismologist" mentioned in the introduction must recognize the need for an integrated view of the complexities of tourism as a starting point for research efforts.

Thus, this article proposes a more structured way of using systems thinking in tourism studies through an integrated terminology. Future research might consist of reviewing existing methodologies or tools, or developing new ones, based on the proposed integrated tourism systems thinking framework, to continue developing a more interconnected body of resources that advance the understanding of tourism as the multifaceted phenomenon that it is.

Finally, it should be noted that our call to embrace the study of tourism as a complex phenomenon through systems thinking is made not merely for the sake of a more integrative academic understanding. The current state of our globalized, interconnected, and increasingly fast-paced world presents new collective challenges. This is the case of the incessant local and global increase in people's mobility out of their usual environment, for whatever reason other than migration - in other words, tourism, which has consequences in different ways for the global population. It is therefore particularly important to spread the idea, from academia to society in general, that addressing these complex challenges requires new ways of referring to current global-scale phenomena.

\section{Acknowledgment}

This article is part of the doctoral research of Juan Santiago Rodríguez-Girón, which was funded by a grant from the Secretaría Nacional de Educación Sperior, Ciencia y Tecnología (SENESCYT) in Ecuador.

\section{References}

Albert, A. (1995). Chaos and society. Amsterdam: IOS Press-Presses de l'Université du Québec.

Arnold, R. D., \& Wade, J. P. (2015). A definition of systems thinking: A systems approach. Procedia Computer Science, 44, 669-678. doi: https://doi.org/10.1016/ j.procs.2015.03.050

Baggio, R. (2008). Symptoms of complexity in a tourism system. Tourism Analysis, 13(1), 1-20. doi: https://doi. org/10.3727/108354208784548797

Baggio, R. (2013). Oriental and Occidental approaches to complex tourism systems. Tourism Planning \& Development, 10(2), 217-227. doi: https://doi.org/10.1080/ 21568316.2013.783731

Baggio, R. (2017). Network science and tourism - the state of the art. Tourism Review, 72(1), 120-131.doi: https:// doi.org/10.1108/TR-01-2017-0008

Benson, A. M., \& Blackman, D. (2011). To distribute leadership or not? A lesson from the islands. Tourism Management, 32(5), 1141-1149. doi: https://doi.org/10.1016/ j.tourman.2010.10.002

Bramwell, B., \& Lane, B. (2013). Getting from here to there: Systems change, behavioural change and sustainable tourism. Journal of Sustainable Tourism, 21(1), 1-4. doi: https://doi.org/10.1080/09669582.2012.741602

Brouder, P., \& Fullerton, C. (2015). Exploring heterogeneous tourism development paths: Cascade effect or co-evolution in Niagara? Scandinavian Journal of Hospitality and Tourism, 15(1-2), 152-166. doi: https://doi. org/10.1080/15022250.2015.1014182

Butler, R. W. (1980). The concept of a tourist area cycle of evolution: Implications for management of resources. 
Canadian Geographer/Le Géographe Canadien, 24(1), 5-12. doi: https://doi.org/10.1111/j.1541-0064.1980. tb00970.x

Chen, Y., Zhang, Z., Huang, J., \& Xie, Y. (2013). Toward a scientific ontology based concept of function. $A I$ $E D A M, 27$ (Special Issue 03), 241-248. doi: https://doi. org $/ 10.1017 / \mathrm{S} 0890060413000243$

Currie, G., \& Lockett, A. (2011). Distributing leadership in health and social care: Concertive, conjoint or collective? International Journal of Management Reviews, 13(3), 286-300. doi: https://doi.org/10.1111/j.1468-2370. 2011.00308.x

Darbellay, F., \& Stock, M. (2012). Tourism as complex interdisciplinary research object. Annals of Tourism Research, 39(1), 441-458. doi: https://doi.org/10.1016/ j.annals.2011.07.002

Dekkers, R. (2015). Applied systems theory. Cham, Switzerland: Springer International Publishing.

d'Hauteserre, A.-M. (2006). A response to 'Tracing the Commodity Chain of Global Tourism' by Dennis Judd. Tourism Geographies, 8(4), 337-342. doi: https://doi. org/10.1080/14616680600922005

Dubois, G., Peeters, P., Ceron, J.-P., \& Gössling, S. (2011). The future tourism mobility of the world population: Emission growth versus climate policy. Transportation Research Part A: Policy and Practice, 45(10), 10311042. doi: https://doi.org/10.1016/j.tra.2009.11.004

Erçetin, Ş. Ş., \& Banerjee, S. (Eds.). (2015). Chaos, complexity and leadership. Cham, Switzerland: Springer International Publishing.

Erkoçak, E., \& Açıkalın, Ş. N. (2015). Complexity theory in public administration and metagovernance. In Ş. Ş. Erçetin \& S. Banerjee (Eds.), Chaos, complexity and leadership (pp. 73-84). Cham, Switzer;and: Springer International Publishing.

Farrell, B. H., \& Twining-Ward, L. (2004). Reconceptualizing tourism. Annals of Tourism Research, 31(2), 274 295. doi: https://doi.org/10.1016/j.annals.2003.12.002

Ford, R. C., Wang, Y., \& Vestal, A. (2012). Power asymmetries in tourism distribution networks. Annals of Tourism Research, 39(2), 755-779. doi: https://doi.org/10.1016/ j.annals.2011.10.001

Forrester, J. W. (2007). System dynamics - the next fifty years. System Dynamics Review, 23(2-3), 359-370. doi: https://doi.org/10.1002/sdr.381

Ghosh, A. (2015). Dynamic systems for everyone. Cham, Switzerland: Springer International Publishing.

Grupo de Investigación en Economía Regional. (2017a). Estudio de la demanda y oferta turística de la ciudad de Cuenca en el año 2016 (Study of the demand and tourist offer of the city of Cuenca in 2016) (Reporte consolidado anual) (p. 113). Cuenca, Ecuador: Fundación Municipal Turismo para Cuenca - Grupo de Investigación en Economía Regional GIER de la Universidad de Cuenca.

Grupo de Investigación en Economía Regional. (2017b). Infografia: Estudio de la demanda y oferta turística de la ciudad de Cuenca en el año 2016 (Infographics: Study of the demand and tourist offer of the city of Cuenca in
2016) (Reporte anual) (p. 11). Cuenca, Ecuador: Fundación Municipal Turismo para Cuenca - Grupo de Investigación en Economía Regional GIER de la Universidad de Cuenca.

Gleick, J. (1987). Chaos. Making a new science. New York, NY: Viking Penguin Inc.

Goeldner, C. R., \& Ritchie, J. R. B. (2003). Tourism: Principles, practices, philosophies (9th ed.). Hoboken, NJ: John Wiley \& Sons, Inc.

Hall, C. M., \& Page, S. J. (2014). The geography of tourism and recreation: Environment, place and space (4th ed.). Oxon, UK: Routledge.

Hartman, S. (2016). Towards adaptive tourism areas? A complexity perspective to examine the conditions for adaptive capacity. Journal of Sustainable Tourism, 24(2), 299-314. doi: https://doi.org/10.1080/09669582.2015.1 062017

Heylighen, F. (2009). Complexity and self-organization. In Encyclopedia of library and information sciences, third edition (pp. 1215-1224). Boca Raton, FL: CRC Press.

Hoff, T. L. (1992). Gall's psychophysiological concept of function: The rise and decline of "internal essence". Brain and Cognition, 20(2), 378-398. doi: https://doi. org/10.1016/0278-2626(92)90028-K

Ioannides, D. (2006). Commentary: The economic geography of the tourist industry: Ten years of progress in research and an agenda for the future. Tourism Geographies, 8(1), 76-86. doi: https://doi.org/10.1080/146166 80500392515

Ioannides, D., \& Debbage, K. G. (1998). The economic geography of the tourist industry: A supply-side analysis. London, UK: Routledge.

Ioannides, D., \& Debbage, K. G. (2014). Economic geographies of tourism revisited from theory to practice. In A. A. Lew, C. M. Hall, \& A. M. Williams (Eds.), The Wiley Blackwell companion to tourism (1st ed., pp. 107-119). Chichester, UK: John Wiley \& Sons, Ltd.

Jafari, J., \& Xiao, H. (Eds.). (2016). Encyclopedia of tourism. Cham, Switzerland: Springer International Publishing.

Jørgensen, M. T. (2017). Reframing tourism distributionActivity theory and actor-network theory. Tourism Management, 62, 312-321. doi: https://doi.org/10.1016/ j.tourman.2017.05.007

Judd, D. R. (2006). Commentary: Tracing the commodity chain of global tourism. Tourism Geographies, 8(4), 323336. doi: https://doi.org/10.1080/14616680600921932

Lansing, P., \& Vries, P. D. (2006). Sustainable tourism: Ethical alternative or marketing ploy? Journal of Business Ethics, 72, 77-85. doi: https://doi.org/10.1007/s10551006-9157-7

Leiper, N. (1979). The framework of tourism: Towards a definition of tourism, tourist, and the tourist industry. Annals of Tourism Research, 6(4), 390-407. doi: https:// doi.org/10.1016/0160-7383(79)90003-3

Leiper, N. (2008). Why 'the tourism industry' is misleading as a generic expression: The case for the plural variation, 'tourism industries'. Tourism Management, 29(2), 237251. doi: https://doi.org/10.1016/j.tourman.2007.03.015 
Lindsay, A., Downs, D., \& Lunn, K. (2003). Business processes - attempts to find a definition. Information and Software Technology, 45(15), 1015-1019. doi: https:// doi.org/10.1016/S0950-5849(03)00129-0

Lohmann, G., \& Netto, A. P. (2017). General systems theory and tourism. In Tourism theory: Concepts, models and systems (pp. 3-7). Oxfordshire, UK: CABI.

Mahner, M., \& Bunge, M. (2001). Function and functionalism: A synthetic perspective. Philosophy of Science, 68(1), 75-94.

Mai, T., \& Smith, C. (2015). Addressing the threats to tourism sustainability using systems thinking: A case study of Cat Ba Island, Vietnam. Journal of Sustainable Tourism, 23(10), 1504-1528. doi: https://doi.org/10.1080/ 09669582.2015 .1045514

Martin, R., \& Sunley, P. (2012). Forms of emergence and the evolution of economic landscapes. Journal of Economic Behavior \& Organization, 82(2-3), 338-351. doi: https://doi.org/10.1016/j.jebo.2011.08.005

McBride, N. (2005). Chaos theory as a model for interpreting information systems in organizations. Information Systems Journal, 15(3), 233-254. doi: https://doi. org/10.1111/j.1365-2575.2005.00192.x

McDonald, J. R. (2009). Complexity science: An alternative world view for understanding sustainable tourism development. Journal of Sustainable Tourism, 17(4), 455-471. doi: https://doi.org/10.1080/09669580802495709

McKercher, B. (2008). The implicit effect of distance on tourist behavior: A comparison of short and long haul pleasure tourists to Hong Kong. Journal of Travel \& Tourism Marketing, 25(3-4), 367-381. doi: https://doi. org $/ 10.1080 / 10548400802508473$

McKercher, B. (2014). Academic myths of tourism. Annals of Tourism Research, 46, 16-28. doi: https://doi.org/ 10.1016/j.annals.2014.02.003

McKercher, B., \& Zoltan, J. (2014). Tourist flows and spatial behavior. In A. A. Lew, C. M. Hall, \& A. M. Williams (Eds.), The Wiley Blackwell companion to tourism (1st ed., pp. 33-44). Chichester, UK: John Wiley \& Sons.

Meekes, J., Parra, C., \& de Roo, G. (2016). Regional development and leisure in Fryslân: A complex adaptive systems perspective through evolutionary economic geography. In P. Brouder, S. A. Clavé, A. Gill, \& D. Ioannides (Eds.), Tourism destination evolution (pp. 149-165). New York, NY: Routledge.

Mella, P. (2009). The holonic revolution. Holons, holarchies and holonic networks. The ghost in the production machine. Pavia, Italy: Pavia University Press.

Mella, P. (2012). Systems thinking: Intelligence in action. Milan, Italy: Springer.

Mill, R. C., \& Morrison, A. M. (1985). The tourism system: An introductory text. Englewood Cliffs, NJ: Prentice Hall.

Milne, S., \& Ateljevic, I. (2001). Tourism, economic development and the global-local nexus: Theory embracing complexity. Tourism Geographies, 3(4), 369-393. doi: https://doi.org/10.1080/146166800110070478
Mingers, J. (2006). Realising systems thinking: Knowledge and action in management science. New York, NY: Springer.

Mosedale, J. (2006). Tourism commodity chains: Market entry and its effects on St Lucia. Current Issues in Tourism, 9(4), 436-458. doi: https://doi.org/10.2167/ cit271.0

Ministerio de Turismo de Ecuador. (2017). Entradas y salidas internacionales 2016, Ecuador. Ecuador: Author

Mura, P., \& Tavakoli, R. (2014). Tourism and social capital in Malaysia. Current Issues in Tourism, 17(1), 28-45. doi: https://doi.org/10.1080/13683500.2012.718320

Nguyen, N. C., Bosch, O. J. H., \& Maani, K. E. (2011). Creating 'learning laboratories' for sustainable development in biospheres: A systems thinking approach. Systems Research and Behavioral Science, 28(1), 51-62. doi: https://doi.org/10.1002/sres.1044

Nicholls, S., Amelung, B., \& Student, J. (2017). Agentbased modeling: A powerful tool for tourism researchers. Journal of Travel Research, 56(1), 3-15. doi: https://doi. org $/ 10.1177 / 0047287515620490$

Nicolau, J. L. (2013). Direct versus indirect channels. European Journal of Marketing, 47(1/2), 260-278. doi: https://doi.org/10.1108/03090561311285547

Papatheodorou, A. (2004). Exploring the evolution of tourism resorts. Annals of Tourism Research, 31(1), 219-237. doi: https://doi.org/10.1016/j.annals.2003.10.004

Pearce, D. G. (2008). A needs-functions model of tourism distribution. Annals of Tourism Research, 35(1), 148168. doi: https://doi.org/10.1016/j.annals.2007.06.011

Pearce, D. G., Tan, R., \& Schott, C. (2007). Distribution channels in international markets: A comparative analysis of the distribution of New Zealand tourism in Australia, Great Britain and the USA. Current Issues in Tourism, 10(1), 33-60. doi: https://doi.org/10.2167/cit290.0

Perkins, H. C., \& Thorns, D. C. (2001). Gazing or performing? Reflections on Urry's tourist gaze in the context of contemporary experience in the Antipodes. International Sociology, 16(2), 185-204. doi: https://doi.org/ $10.1177 / 0268580901016002004$

Pike, S., \& Page, S. J. (2014). Destination marketing organizations and destination marketing: A narrative analysis of the literature. Tourism Management, 41, 202-227. doi: https://doi.org/10.1016/j.tourman.2013.09.009

Ritchie, J. R. B., \& Crouch, G. I. (2003). The competitive destination: A sustainable tourism perspective. Wallingford, UK: CABI.

Rodriguez-Giron, S., Vanneste, D., \& Ioannides, D. (2018). An integrative model (iModel) for decision-making in tourism. Tourism Planning \& Development, 1-19. doi: https://doi.org/10.1080/21568316.2018.1506818

Russell, R., \& Faulkner, B. (1999). Movers and shakers: Chaos makers in tourism development. Tourism Management, 20(4), 411-423. doi: https://doi.org/10.1016/ S0261-5177(99)00014-X

Smith, S. L. J. (1994). The tourism product. Annals of Tourism Research, 21(3), 582-595. doi: https://doi.org/ 10.1016/0160-7383(94)90121-X 
Speakman, M. (2016). A paradigm for the twenty-first century or metaphorical nonsense? The enigma of complexity theory and tourism research. Tourism Planning \& Development, 14(2), 282-296. doi: https://doi.org/10.1080/ 21568316.2016.1155076

Thomas, R., Shaw, G., \& Page, S. J. (2011). Understanding small firms in tourism: A perspective on research trends and challenges. Tourism Management, 32(5), 963-976. doi: https://doi.org/10.1016/j.tourman.2011.02.003

Tribe, J., \& Liburd, J. J. (2016). The tourism knowledge system. Annals of Tourism Research, 57(Supplement C), 44-61. doi: https://doi.org/10.1016/j.annals.2015.11.011

TurisConsulting, \& ICOPMED Travel Cia. Ltda. (2016). Libro 1-Plan Estratégico de Desarrollo Turístico y Mercadeo del destino Cuenca y su área de Influencia 2016-2021 (No. Libro 1, p. 115). Cuenca, Ecuador: Fundación Municipal Turismo para Cuenca.

United Nations, \& United Nations World Tourism Organization. (2010). International recommendations for tourism statistics 2008. New York, NY: Author.
United Nations World Tourism Organization. (2014, February). Glossary of tourism terms. New York, NY: Author.

Urry, J., \& Larsen, J. (2011). The tourist gaze 3.0 (3rd ed.). London, UK: SAGE.

Van der Duim, R., \& Caalders, J. (2008). Tourism chains and pro-poor tourism development: An actor-network analysis of a pilot project in Costa Rica. Current Issues in Tourism, 11(2), 109-125. doi: https://doi.org/10.2167/ cit312.0

Van der Duim, R., Ren, C., \& Jóhannesson, G. T. (2013). Ordering, materiality, and multiplicity: Enacting ActorNetwork Theory in tourism. Tourist Studies, 13(1), 3-20. doi: https://doi.org/10.1177/1468797613476397

Zahra, A., \& Ryan, C. (2007). From chaos to cohesionComplexity in tourism structures: An analysis of New Zealand's regional tourism organizations. Tourism Management, 28(3), 854-862. doi: https://doi.org/10.1016/ j.tourman.2006.06.004 